\title{
UM OLHAR SOBRE O PLANEJAMENTO E DESENVOLVIMENTO DO MUNICÍPIO DE SÃO JOÃO DE MERITI/RJ.
}

\author{
Douglas Monteiro de Almeida ${ }^{1}$
}

\section{Carlos Leonardo Gomes Fernandes ${ }^{2}$}

\begin{abstract}
RESUMO
O desenvolvimento de uma região está relacionado com o seu processo histórico de formação e a maneira de como foi conduzida a ocupação de seus espaços livres. São João de Meriti é uma cidade inserida na dinâmica regional da baixada fluminense, e, que necessita de um planejamento urbano para tentar recuperar paisagisticamente e ambientalmente o que foi distorcido por uma ocupação altamente devastadora e sem controle. Uma cidade que séculos passados era formada por fazendas, numa economia baseada na produção agrícola, tem no século XXI seu território totalmente urbano, o que difere da expressão urbanizada. Cercado por diversos rios que diretamente ou indiretamente deságuam na Baia de Guanabara, possui apenas uma pequena área de preservação ambiental retratando todo um processo de desordem urbana. Nesse contexto, este trabalho surge com o intuito de abrir uma agenda local sobre o planejamento urbano municipal. Mas para que isto seja possível inicialmente faz-se necessária uma apresentação das características históricas do município em questão; e nas seções posteriores, a análise de alguns dados que refletem o cenário atual da localidade.
\end{abstract}

PALAVRAS-CHAVE: Desenvolvimento. Planejamento. Preservação.

\section{A LOOK ON THE CITY PLANNING AND DEVELOPMENT SÃO JOÃO DE MERITI/RJ.}

\begin{abstract}
The development of a region is related to its historical process of formation and the way it was conducted the occupation of their open spaces. St. Johns Wood is a city inserted into the regional

\footnotetext{
${ }^{1}$ Economista, mestrando em Desenvolvimento Territorial e Políticas Públicas / UFRRJ. Bolsista CAPES. Douglas_pedropaulo@hotmail.com.

${ }^{2}$ Geógrafo, mestrando em Desenvolvimento Territorial e Políticas Públicas / UFRRJ. Bolsista CAPES. carleofernandes@ig.com.br.
} 


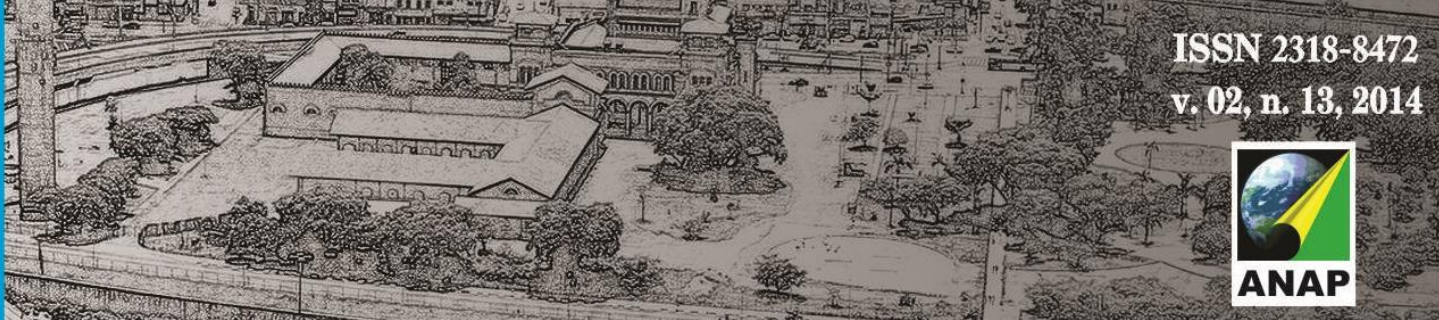

\section{Revista Nacional de}

Gerenciamento de Cidades

dynamics of the Baixada Fluminense, and that needs an urban planning to try to recover landscaped and environmentally which was distorted by a highly devastating occupation and without control. A city that past centuries consisted of farms, an economy based on agricultural production, in the XXI century has its completely urban territory, which differs from the urban expression. Surrounded by several rivers that directly or indirectly flow into the Bay of Guanabara, only has a small area of environmental preservation portraying a whole process of urban disorder. In this context, this paper comes up with the intention of opening a local directory on the municipal urban planning. But for this to be possible initially it is necessary a presentation of the historical characteristics of the municipality in question; and in later sections, the analysis of some data that reflects the current scenario of locality.

KEYWORDS: Development. Planning. Preservation.

\section{UNA MIRADA EN LA PLANIFICACIÓN DE LA CIUDAD Y EL DESARROLLO SÃO JOÃO DE MERITI/RJ.}

\section{RESUMEN}

El desarrollo de una región está relacionada con su proceso histórico de la formación y la forma en que se llevó a cabo la ocupación de sus espacios abiertos. St. Johns Wood es una ciudad inserta en la dinámica regional de la Baixada Fluminense, y que necesita una planificación urbana para tratar de recuperar paisajístico y ambiental que fue distorsionada por una ocupación altamente devastadora y sin control. Una ciudad que siglos pasados consistieron en granjas, una economía basada en la producción agrícola, en el siglo XXI tiene su territorio completamente urbano, que difiere de la expresión urbana. Rodeado de varios ríos que directa o indirectamente desembocan en la Bahía de Guanabara, sólo tiene una pequeña zona de preservación del medio ambiente que retrata todo un proceso de desorden urbano. En este contexto, este artículo viene con la intención de abrir un directorio local en el planeamiento urbanístico municipal. Pero para que esto sea posible es necesario inicialmente una presentación de las características históricas del municipio de que se trate; y en las secciones posteriores, el análisis de algunos datos que refleja el escenario actual de la localidad.

PALABRAS CLAVE: Desarrollo. Planificación. Preservación.

\section{INTRODUÇÃO}

Para entender um município e como constituiu o processo de formação territorial e as consequências das políticas públicas de diversas áreas (entre elas as ambientais) para o desenvolvimento local é preciso de muito debate e procura de algumas ideias para poder alcançar os objetivos.

A Baixada Fluminense é um conjunto de municípios situados na Região Metropolitana do Rio de Janeiro. Alguns desses municípios estão ao lado da capital do Estado, o que torna estes muito dependentes da cidade do Rio de Janeiro. É uma 


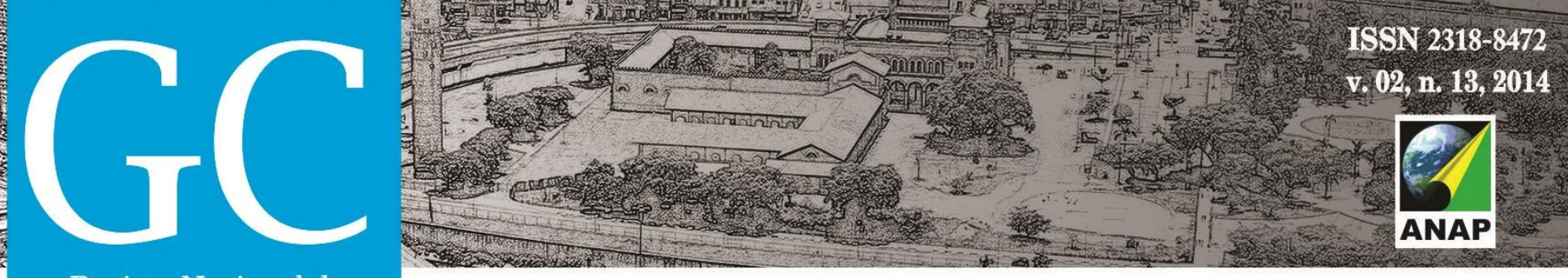

Revista Nacional de

Gerenciamento de Cidades

região que carece de infraestrutura, de serviços básicos, de um planejamento urbano que vise às características ambientais, principalmente hidrográficas da região e carece principalmente de estudos acadêmicos, onde influencia diretamente em achar uma definição para sua composição, se tornando algo difícil e contraditório entender os principais aspectos da região. A divisão político administrativa do Governo do Estado do Rio de Janeiro considera que a Baixada Fluminense é formada por 13 municípios: Duque de Caxias, Guapimirim, Itaguaí, Japeri, Magé, Mesquita, Nilópolis, Nova Iguaçu, Paracambi, Queimados, São João de Meriti e Seropédica.

O município estudado nesse artigo é o de São João de Meriti, que foi escolhido por três motivos. Primeiro, por estar localizado na região da Baixada Fluminense. Segundo, como foi dito anteriormente, pela sua carência de interesse e estudos acadêmicos. Terceiro, devido aos sérios problemas de planejamento urbano e consequentemente de desenvolvimento local, sendo facilmente visualizados por quem vive e passa pela Rodovia Presidente Dutra, Linha Vermelha e outras vias que cortam o município.

Como é de conhecimento de quem estuda políticas públicas existem diversas definições e desdobramentos para o assunto abordado neste trabalho. Segundo SECCHI (2010, p. 2) as definições a respeito de políticas públicas são arbitrárias, não existindo um consenso entre elas. Uma definição usual para política pública seria as ações, metas e planos governamentais feitos para atingir o bem-estar da sociedade e o interesse público.

Desmembrando o tema, desenvolvimento também tem algumas definições distintas, ressalto o que apresenta Vasconcelos; Garcia (1998, p. 205) que acreditam que o desenvolvimento deve incluir "as alterações da composição do produto e a alocação de recursos pelos diferentes setores da economia, de forma a melhorar os indicadores de bem-estar econômico e social (pobreza, desemprego, desigualdade, condições de saúde, alimentação, educação e moradia)". O processo de desenvolvimento, tanto social como econômico de determinada região, depende 
Revista Nacional de

Gerenciamento de Cidades

de diversos fatores e, sobretudo, de políticas públicas inerentes a esse desenvolvimento.

\section{HIPÓTESES E QUESTIONAMENTOS}

Num ambiente totalmente urbano e sem planejamento é difícil mensurar quais políticas seriam necessárias para um ordenamento urbano visando uma redução drástica nos impactos ambientais e na melhora da qualidade de vida da população, como saneamento básico e planejamento urbano. Os problemas existentes em São João de Meriti seriam retrato de um mau planejamento local ou esse mau planejamento surge também do pouco investimento histórico em regiões periféricas?

Uma temática de difícil acesso pela falta de referencias é algo assustador, mas também com um grande caráter motivador. Seria interesse dos órgãos públicos mostrarem de maneira mais corriqueira os problemas dessa região? Se os dados fossem apresentados com certa frequência, os problemas seriam mais explanados o que geraria uma maior intervenção da sociedade.

Logo, a hipótese lançada nesta pesquisa é que uma área como São João de Meriti é de grande importância para toda a região metropolitana do Rio de Janeiro, e assim sendo, precisa de um espaço urbano bem orientado para alocar moradias para os trabalhadores da capital. Muitos dos que vivem nessa cidade ajudam a construir e manter a rotina da cidade maravilhosa, sem ocupar os espaços de moradia do Rio de Janeiro que são altamente "inflacionados".

\section{OBJETIVOS}

\subsection{OBJETIVO GERAL}

- Discutir como São João de Meriti, num processo de constante transformação, é apresentado para seu cidadão e de que forma se 


\section{Revista Nacional de}

constituiu historicamente o processo de planejamento e desenvolvimento, ressaltando algumas consequências paisagísticas e no planejamento.

\subsection{OBJETIVOS ESPECÍFICOS}

- Apresentar a formação histórica do município.

- Discutir a urbanização em São João de Meriti e o impacto dela no meio ambiente.

\section{METODOLOGIA}

Para realizar qualquer pesquisa é necessário apresentar alguma metodologia. E sobre este aspecto fundamental da análise científica Gerhardt \& Silveira (2009, p.12) observam a metodologia como "o estudo da organização, dos caminhos a serem percorridos para se realizar uma pesquisa ou um estudo, ou para se fazer ciência. Etimologicamente, significa o estudo dos caminhos, dos instrumentos utilizados para fazer uma pesquisa científica" (GERHARDT; SILVA p. 12).

Desta forma, pensar no caminho que fez parte da construção desta pesquisa tangencia a utilização de fontes secundárias que foram fundamentais, dado o caráter experimental desse artigo. E no tocante fundamentação teórica, foram utilizadas algumas das bibliografias disponíveis em livros, publicações, revistas, artigos e sites especializados, para alcançar o entendimento dos conceitos utilizados e alguns dados referentes ao município de São João de Meriti. suas relações com os objetivos citados. As outras atividades desenvolvidas foram a análise de literatura pertinente para poder sintetizar as aspirações do tema em torno de categorias de análise. 


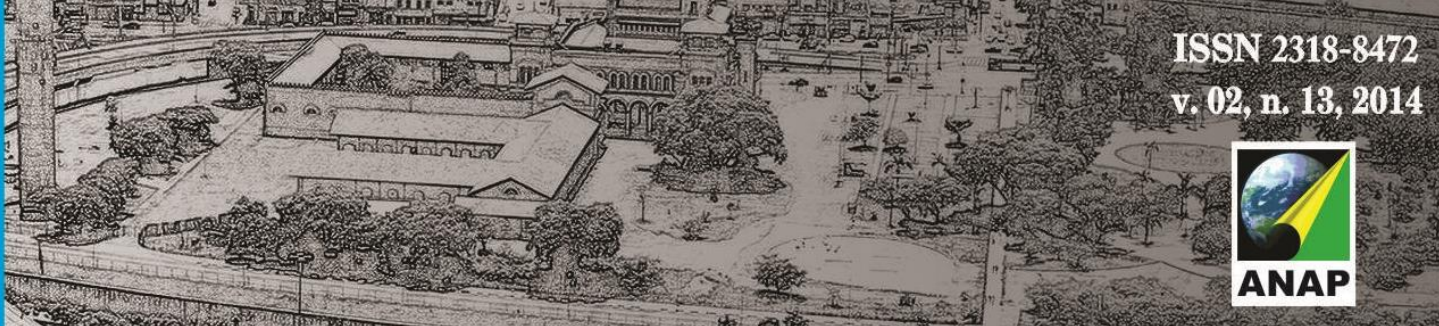

Revista Nacional de

Gerenciamento de Cidades

\title{
5. SÃO JOÃO DE MERITI - RIO DE JANEIRO
}

\subsection{HISTÓRIA}

A ocupação em São João de Meriti começou como de costume em todo Brasil, uma Igreja foi construída à beira do rio Meriti como afirmação do povoado que se formava naquele espaço de produção agrícola de milho e principalmente canade-açúcar, firmado neste local pela proximidade da Zona Portuária da Pavuna, num período que o rio Pavuna e o rio Meriti eram navegáveis. A prefeitura de São João de Meriti diz que ao lado das muitas fazendas existentes, os rios Miriti e Sarapuí eram as principais vias de transporte das mercadorias que eram produzidas. Havia 14 portos nas margens desses rios, com um grande serviço de canoagem.

\begin{abstract}
Anos depois o processo de colonização foi marcado pela instalação de uma capela. Esta foi construída em 1647 no sítio de Trairaponga e funcionou como matriz durante alguns anos até a mudança do centro do povoado para a Zona Portuária, localizada no arraial de Nossa Senhora do Desterro da Pavuna. Em 1660, somente quase um século depois, a nova igreja foi construída às margens do rio Meriti. No entanto, em função da rápida decadência dessa capela, a freguesia passou a ter sua sede na capela de Nossa Senhora da Conceição na área do porto, por volta de 1708. E nesse mesmo período que a Freguesia de São João Batista de Trairaponga, muda seu nome para São João Batista de Meriti. (ABM, 1985, p.10)
\end{abstract}

É possível ver que a formação territorial de São João de Meriti começou da mesma forma que a lógica da época, a construção da cidade próxima ao local de escoamento de mercadorias, numa lógica onde ROSS (1998, p.400) afirma que "cidade é o lugar de trocas. Trocas materiais antes de tudo: o lugar mais favorável a distribuição dos produtos da terra, à produção dos produtos manufaturados e industriais e, enfim, ao consumo dos bens e serviço os mais diversos." Era necessário o crescimento da cidade à beira do rio para escoamento de mercadorias para a cidade do Rio de Janeiro. Anos mais tarde essa lógica muda com a chegada da linha férrea, que vira a mais importante rota de escoamento de produtos. 


\section{Revista Nacional de}

O processo de formação e consistência do povoado foi bem complicado, foi bem sujeito a variações constantes de uma época onde se valorizava, até mesmo constitucionalmente, mais o centro político e econômico do que as outras regiões no entorno. Essa inconsistência fez com que essa região demorasse a ser vista como possível local de expansão e crescimento.

A Freguesia de São João Batista de Meriti juntamente com o povoado Maxambomba (Nova Iguaçu) eram passagem obrigatória no caminho para o sertão mineiro. São João de Meriti declinou no século XIX, ficando esquecido até mesmo dos mapas. A decadência veio de um mau planejamento que devido o constante desmatamento os rios da região começaram a ficar assoreados o que causava enchentes e pântanos na região.

No final do século XIX e inicio do século XX que essa região voltou a crescer com a chegada das estradas de ferro. "Em 1892 a Freguesia de São João de Meriti é incorporada ao Município de Iguaçu como $4^{\circ}$ Distrito." (ABM, 1985, p.12) Com a ascensão da antiga Freguesia de Nossa Senhora do Pilar (Duque de Caxias) e sua posterior emancipação, Meriti passou a ser $2^{\circ}$ Distrito de Duque de Caxias.

\subsection{DADOS REFERENTES AO MUNICÍPIO}

São João de Meriti é um município brasileiro, localizado na Baixada Fluminense, Rio de Janeiro. Segundo informações do Censo 2010 sua população era de 458.673 mil habitantes, com estimativa de 460.799 habitantes no ano de 2013. O índice de desenvolvimento humano (IDH) é de 0,719 , abaixo da média nacional. O município tem aproximadamente $35 \mathrm{~km}^{2}$ e uma densidade demográfica de 13.024,56 habitantes $/ \mathrm{km}^{2}$, a maior do Brasil. 


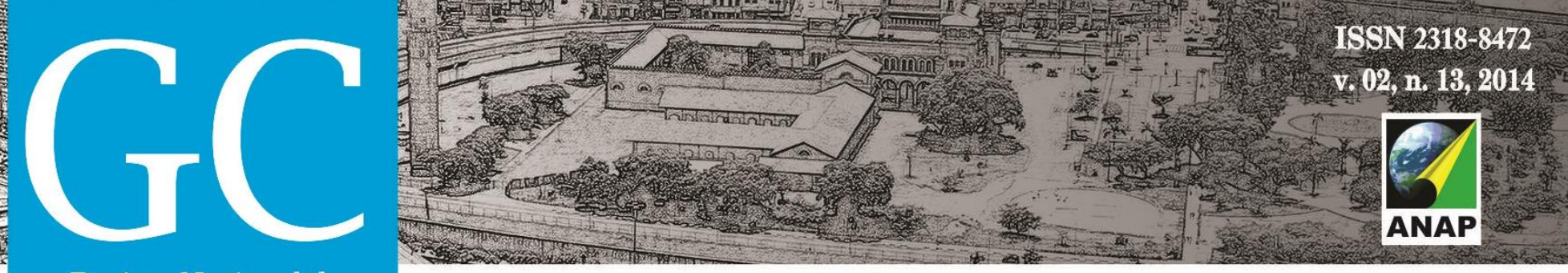

\section{Revista Nacional de}

Gerenciamento de Cidades

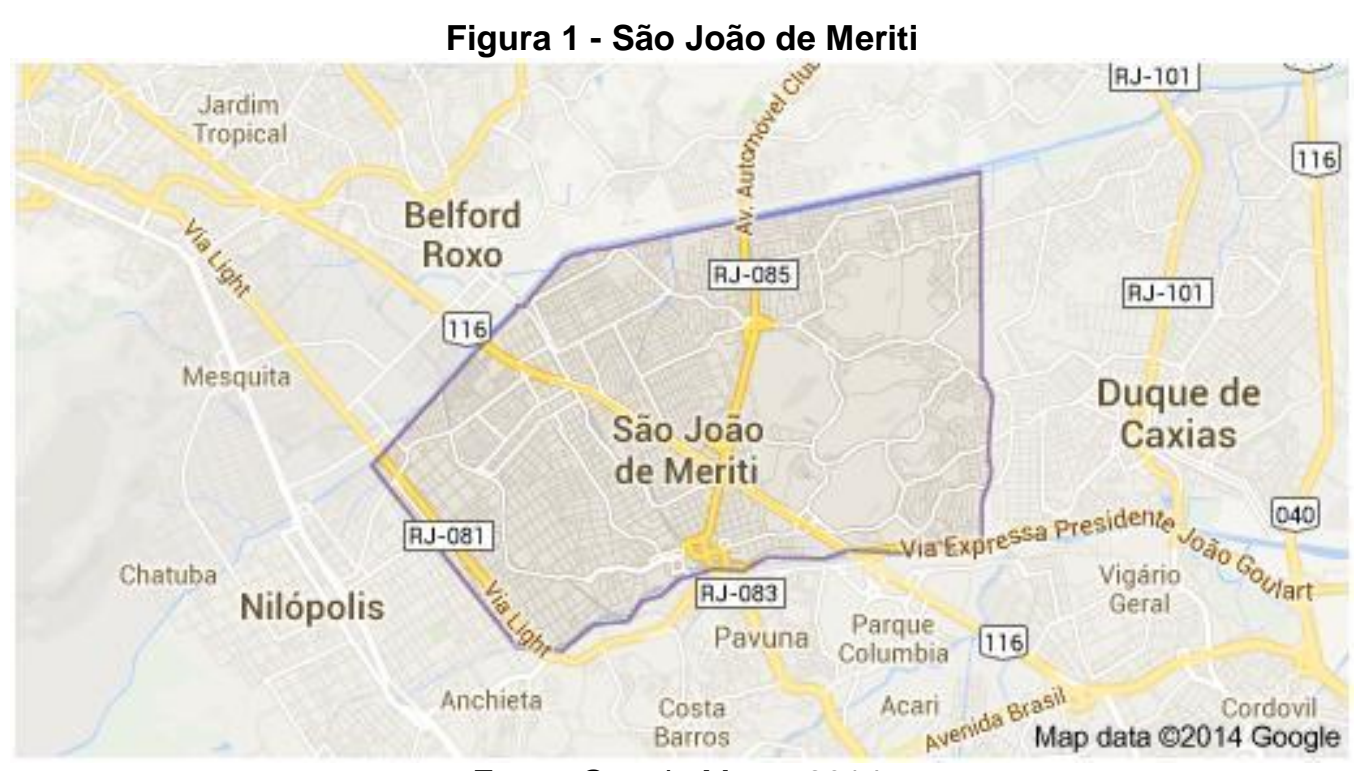

Fonte: Google Maps, 2014.

Na Figura 1, encontra-se representado o mapa de São João de Meriti e os municípios limítrofes, Belford Roxo, Nilópolis, Duque de Caxias, Mesquita e Rio de Janeiro. Os principais eixos viários que cortam a cidade são a Rodovia Presidente Dutra (BR 116), a Via Expressa Presidente João Goulart (Linha vermelha), a Via Light e a Avenida Automóvel Clube.

O território meritiense tem aproximadamente $35 \mathrm{~km}^{2}$ para uma população de mais de 460 mil habitantes em 2013. A primeira constatação nessa afirmativa é simples, tem muitas pessoas nesse município para pouco espaço. A segunda é que devido a essa limitação geográfica e o grande contingente populacional o município possui poucos espaços livres. Toda população residente no município de São João de Meriti está alocada em área urbana. O inciso IV do artigo 24 do Plano Diretor de São João de Meriti ressalta a importância da criação de áreas verdes, frente essa forte concentração urbana.

IV - a aridez atual de seu território ocupado e a necessidade de renaturalizar a região através da criação e manutenção de novas áreas verdes, parques, praças e maior permeabilidade do solo, amenizando o clima reinante, através da arborização, corredores verdes e atração de uma fauna urbana complementar à vida urbana.(Lei 089, 2006) 


\title{
Revista Nacional de
} Gerenciamento de Cidades

\begin{tabular}{c|c|c}
\multicolumn{3}{c}{ Tabela 1 - Crescimento populacional } \\
Ano & População residente & Crescimento em \%. \\
\hline 1940 & 39.569 & \\
\hline 1950 & 76.462 & $93,24 \%$ \\
\hline 1960 & 191.734 & $150,76 \%$ \\
\hline 1970 & 302.394 & $57,72 \%$ \\
\hline 1980 & 398.689 & $31,84 \%$ \\
\hline 1991 & 425.772 & $6,79 \%$ \\
\hline 1996 & 433.759 & $1,88 \%$ \\
\hline 2000 & 449.476 & $3,62 \%$ \\
\hline 2007 & 464.282 & $3,29 \%$ \\
\hline 2010 & 458.673 & $-1,21 \%$ \\
\hline & \multicolumn{3}{c}{ Fonte: Elaboração própria, IBGE. }
\end{tabular}

A população de São João de Meriti sempre seguiu um movimento de crescimento se comparado intervalos de 10 anos. A partir de 1990 essa taxa de crescimento populacional diminuiu devido à ocupação quase que total do município. Até a década de 1970 esse movimento foi grande devido à chegada de muitos migrantes nordestinos que ao chegar ao Rio de Janeiro não encontraram moradia barata e foram buscar essa moradia na Baixada Fluminense.

\begin{abstract}
O grande fluxo de migrantes, principalmente de nordestinos, após a década de 50 do século XX em direção ao Rio de Janeiro, na busca de melhores condições de vida e oportunidade de trabalho promovida pela industrialização, acarretou na ocupação da periferia, já que o Rio de Janeiro não apresentou capacidade suficiente nem tão pouco planejamento para absorver esse contingente populacional, associado ao alto custo da moradia imposto pelo mercado imobiliário excluindo a população de baixa renda, restando a ela procurar as áreas periféricas localizadas mais próximas ao Rio de Janeiro, transformando as mesmas em cidades dormitórios. (FIGUÊREDO, 2004, p.14)
\end{abstract}

Para se entender os conceitos de urbanização e crescimento urbano é bom definir antes o conceito de cidade. Para SANTOS (1994, p.10), "a cidade em si, como relação social e como materialidade, torna-se criadora de pobreza, tanto pelo modelo socioeconômico de que é suporte como por sua estrutura física que fazem dos habitantes das periferias pessoas ainda mais pobres". 


\section{Revista Nacional de}

Gerenciamento de Cidades

O que muitos não sabem é que existe uma diferença nas expressões urbanização e crescimento urbano. Existe uma tendência de ligar essas palavras num único significado, mas cada uma possui sua especificidade. A urbanização está relacionada ao aumento proporcional da população urbana em relação à população rural, um processo social de mudanças comportamentais que ocorrem na sociedade, como resultado das pessoas morando em cidades. Já Crescimento Urbano é o aumento da área urbana de uma cidade.

\subsection{CIDADE DORMITÓRIO}

Numa análise sobre o real significado de cidade dormitório é necessário verificar quais tipos de cidades existem na sociedade contemporânea e em qual contexto a cidade dormitório se encaixa. FREITAG (2002) apresenta cinco tipos de cidades contemporâneas: as cidades globais, as megalópoles, as metrópoles, as cidades periféricas e as cidades-dormitório. Ele define cidade-dormitório como o mesmo que cidade satélite. Para ele quem mora nessas cidades não se consideram cidadão da mesma, pois se naquele local não se encontra o seu trabalho e só serve como dormitório e residência, ele não teria compromisso efetivo com a cidade. Além disso, a cidade-dormitório não teria sua independência administrativa nem econômica própria o que a tornaria dependente da sede regional.

Comparando com que "FREITAG" apresenta como cidade dormitório, podemse encontrar semelhanças relativas ao processo ocorrido historicamente em Meriti. Uma população que usa o município apenas para dormir, resultado da necessidade da cidade vizinha, Rio de Janeiro, em contar com uma ampla mão de obra.

Nas décadas de 1930 e 1940 com o declínio da produção agrícola em São João de Meriti começaram a surgirem as características da cidade dormitório. Segundo a $\mathrm{ABM}^{3}$ (1985) duas condições foram determinantes para a cidade "crescer": os baixos custos dos terrenos e a proximidade da capital do Rio de

\footnotetext{
${ }^{3}$ Federação das Associações de Moradores de São João de Meriti.
} 


\section{Revista Nacional de}

Gerenciamento de Cidades

causadas pelo assoreamento dos rios que cortam e delimitam a cidade, serão definidos alguns conceitos importantes, como APP e Unidades de Conservação.

\subsubsection{UNIDADES DE CONSERVAÇÃO}

Segundo o Ministério do Meio Ambiente, Unidades de Conservação (UC) são espaços de território com características naturais relevantes e limites definidos. Elas são instituídas pelo Poder Público para garantir a proteção e conservação dessas características naturais. Existem dois tipos de unidades de conservação, a de proteção integral, que garante a preservação total da natureza, e a de uso sustentável, que permitem seu uso controlado. Segundo o Ministério do Meio Ambiente as Áreas de Preservação Permanente (APP) foram instituídas pelo Código Florestal (Lei no 4.771 de 1965 e alterações posteriores) e são os espaços territoriais legalmente protegidos, frágeis e vulneráveis ambientalmente, tanto em áreas públicas ou privadas, urbanas ou rurais, cobertas ou não por vegetação nativa.

São João de Meriti possui uma unidade de conservação na categoria de Parque. O parque Natural Municipal Jardim Jurema foi instituído pelo Decreto oㅡ 4220/2004, de 16/11/2010 com o objetivo de preservar e conservar o ecossistema existente. O bioma declarado é de Mata Atlântica. Ele tem uma área de aproximadamente 15 hectares. O Parque é aberto a visitações, no entanto, até 2014 o Parque foi pouco visitado devido a pouca divulgação da existência do mesmo. 

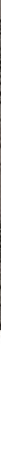

Gerenciamento de Cidades

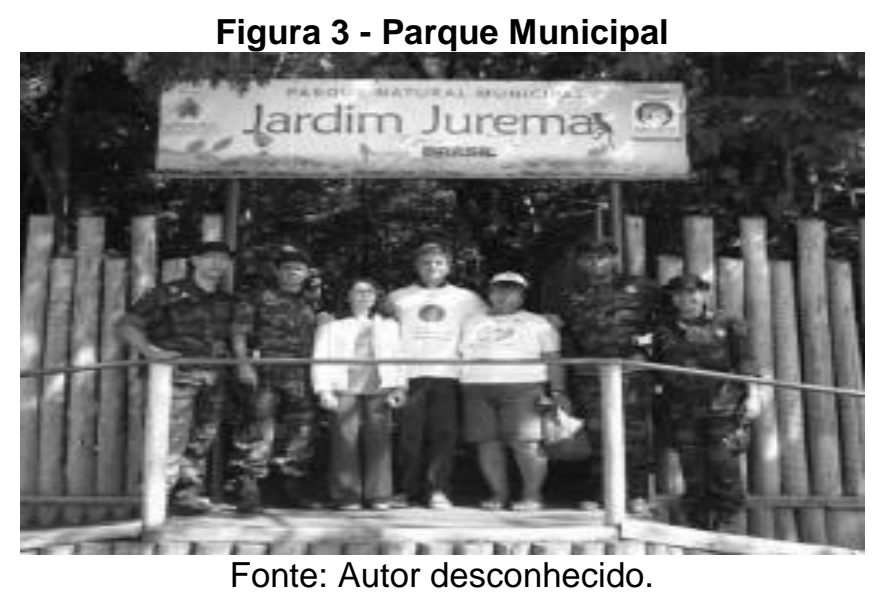

Figura 4 - Parque Municipal

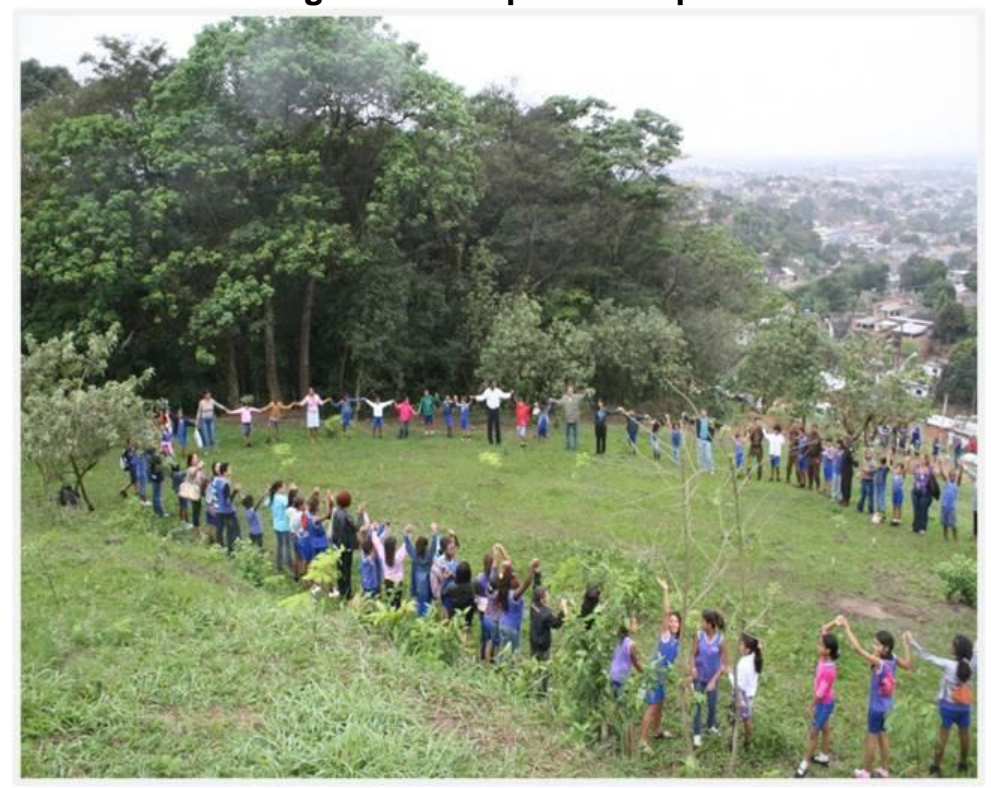

Fonte: Autor desconhecido.

As fotos acima retratam a entrada do Parque e um espaço gramado no ano de 2010. Pela forma de ocupação no município essa área é de muita importância para manter um espaço de preservação dentro de um território altamente povoado e edificado.

\subsubsection{PROBLEMAS}

O Plano de Contingência para os riscos relacionados às chuvas em São João de Meriti apresenta diversos problemas e dificuldades, a população meritiense que 


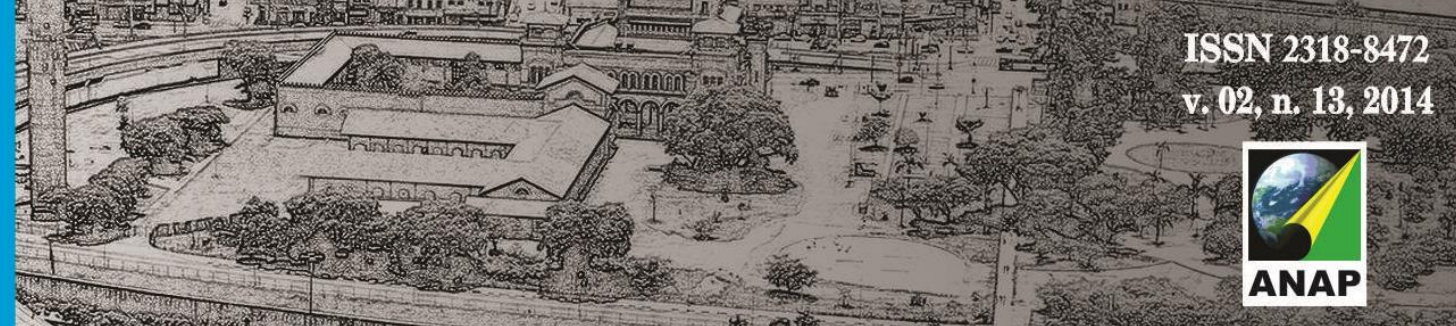

\section{Revista Nacional de}

Gerenciamento de Cidades

vive em áreas de risco sofre pela falta de infraestrutura e planejamento. Esse relatório mostra uma estimativa de risco nas áreas mais vulneráveis a escorregamentos ou deslizamentos, onde se destaca que 5.515 casas encontram-se em diferentes níveis de risco, podendo assim gerar aproximadamente danos humanos, na ordem de 19.540 pessoas afetadas, 4,5\% da população sofre diretamente com a falta de planejamento.

O relatório apresenta que o Município vem sofrendo uma intensa expansão urbana, sem um planejamento adequado do uso do solo. E essa ocupação desordenada nas áreas de encosta da cidade, com construções de casas sem direcionamento técnico, associada à falta de percepção de risco da população e a condição social são agravantes em relação aos eventos de movimentos gravitacionais de massa, enchentes e inundações.

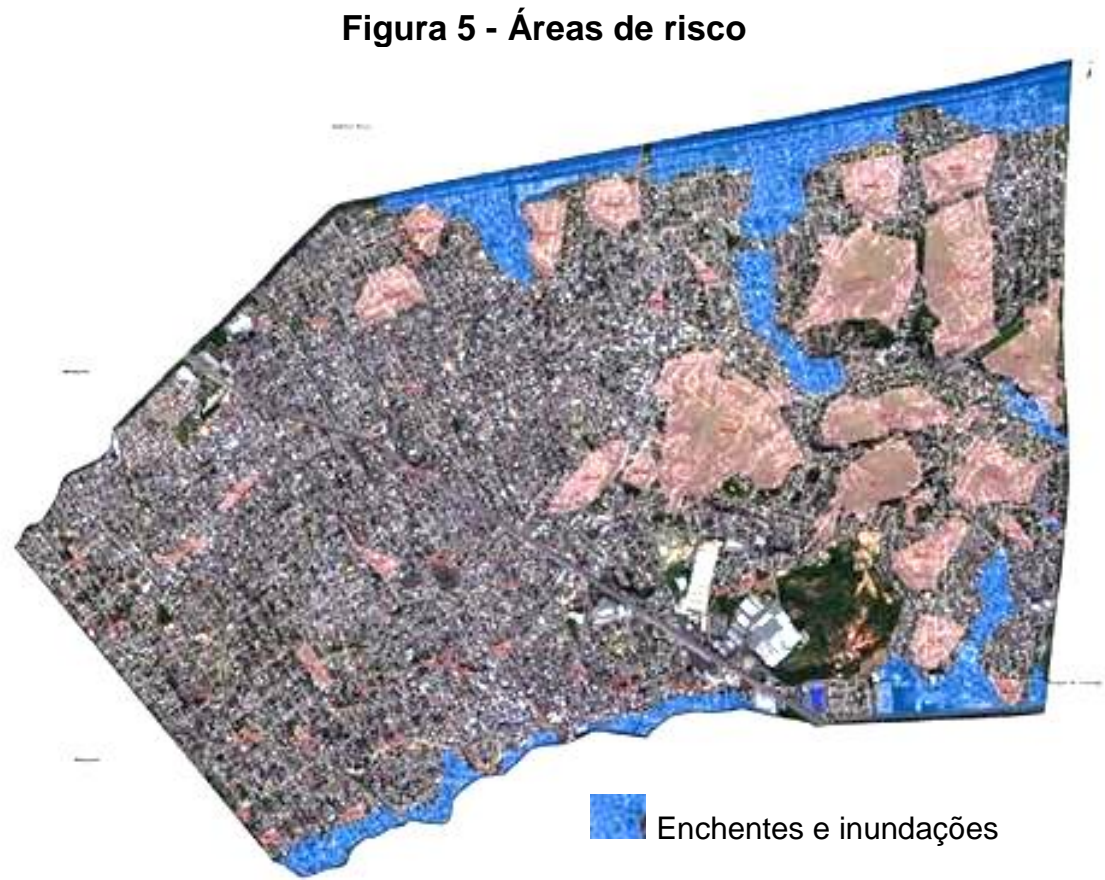

Fonte: Prefeitura de São João de Meriti.

O mapa acima demonstra as áreas de risco do município. As localidades marcadas em azul são com potenciais riscos de enchente a alagamento devido a 


\section{Revista Nacional de}

Gerenciamento de Cidades

proximidade com os principais rios. Já as regiões destacadas em rosa claro são as suscetíveis a deslizamento de terra.

O problema das enchentes em Meriti é um processo histórico decorrente de uma região que nunca teve um rigoroso estudo e planejamento de suas áreas. Desde os séculos XVIII e XIX esse território foi explorado sem nenhuma reposição de seus recursos ou manutenção de sua vegetação tanto nas encostas como nas margens dos rios, o que depois, com a falência da agricultura na região, se transformou numa área de ocupação sem regras, com diversos loteamentos em áreas de pântano e mais tarde em encostas de morros.

A Unidade de Conservação é o único refugio concentrado de área verde presente no município, como pôde ser visto no mapa apresentado no corpo do artigo. Sendo assim, é necessária a constante intervenção do Estado e o cuidado para que não haja invasões nessa área e possíveis construções que passem a delimitação da área de conservação.

\section{CONCLUSÕES}

Pode-se concluir que São João de Meriti precisa de mais estudos referentes aos impactos ambientais causados por uma urbanização e crescimento urbano sem nenhum controle, o que ocasionou diversos prejuízos que são sentidos diariamente por boa parcela da população que vive em morros, na beira de rios ou em baixadas, que compõe as principais áreas de riscos do município. Na verdade, toda a região da Baixada Fluminense carece desses estudos, não só na área do planejamento e desenvolvimento regional e local, mas em diversas áreas e perspectivas, a academia tem que olhar mais para essas localidades. A dificuldade de coletar dados e informações sobre o município demonstram a necessidade de uma maior importância e olhar mais cuidadoso para toda a região. Os habitantes desse município ficam praticamente largados de lado diante da falta de planejamento urbano para sua cidade, causado devido a falta de responsabilidade e total descaso principalmente de seu governo local. 


\section{Revista Nacional de}

Gerenciamento de Cidades

Tendo em vista o Plano Diretor apresentado em 2006, sobre o aspecto da criação de áreas verdes, a Unidade de Conservação pode ser considerada afirmação dessa proposta apresentada, na tentativa de frear a total extinção de ambientes naturais no município.

Os problemas existentes em São João de Meriti não são específicos somente desse município, mas sim de uma lógica existente em todo país de criar territórios periféricos nas regiões metropolitanas, locais com pouca assistência, criados de loteamento de baixo custo para suprir a necessidade de moradia da mão de obra das capitais, processo contínuo e desbravador que vai criando periferias dentro de periferias.

\section{REFERÊNCIAS}

ABM - FEDERAÇÃO DAS ASSOCIAÇÕES DE MORADORES DE SÃO JOÃO DE MERITI. Nesta história, nossa vida. São João de Meriti. Rio de Janeiro: Fase, 1985.

BRASIL. Ministério do Meio Ambiente. Áreas de Preservação Permanente Urbanas. Disponível em $<$ www.mma.gov.br> Acessado em Mai 2014.

Disponível em <www.mma.gov.br> Acessado em Mai 2014.

Cadastro Nacional de Unidades de Conservação.

Figueredo, M. A. Gênese e (Re)produção do Espaço na Baixada Fluminense. Revista geopaisagem. 2004

GERHARDT, T. E., \& SILVEIRA, D. T. Métodos de Pesquisa. Porto Alegre: UFRGS, 2009. INSTITUTO BRASILEIRO GEOGRAFIA E ESTATÍSTICA - IBGE. Atlas do censo demográfico 2010. Rio de Janeiro: IBGE, 2013. Disponível em <www.ibge.gov.br> Acessado em Mar 2013.

SANTOS, Milton. A urbanização Brasileira. São Paulo: Hucitec, 1993.

SÃO JOÃO DE MERITI, Prefeitura Municipal. Plano de contingência de proteção e defesa civilPLANCON.São João de Meriti.2013.

SÃO JOÃO DE MERITI. Lei complementar no 089, de 21 de novembro de 2006. Estabelece o Plano Diretor do Município de São João de Meriti. São João de Meriti, 2006.

SECHI, Leonardo. Políticas públicas: conceitos, esquema de análise, casos práticos. São Paulo: Cengage Learning, 2010.

ROSS, Jurandyr L. S. (org) Geografia do Brasil. São Paulo: Edusp, 1998.

VASCONCELOS, M. A.; GARCIA, M. E. Fundamentos de economia. São Paulo: Saraiva, 1998. 